\title{
OBN for pre-salt imaging and reservoir monitoring - Potential and road ahead
}

Luis Cypriano*, Ziqin Yu, Denis Ferreira, Benjamin Huard, Roberto Pereira, Florian Jouno, Adel Khalil (CGG), Eduardo Naomitsu Agapito Urasaki, Nathalia Martinho Souto Muniz da Cruz (Petrobras), Ailin Yin, Dan Clarke (Shell), Carlos Cardeal Jesus (Petrogal Brasil)

Copyright 2019, SBGf - Sociedade Brasileira de Geofísica

This paper was prepared for presentation during the $16^{\text {th }}$ International Congress of the Brazilian Geophysical Society held in Rio de Janeiro, Brazil, 19-22 August 2019.

Contents of this paper were reviewed by the Technical Committee of the $16^{\text {th }}$ International Congress of the Brazilian Geophysical Society and do not necessarily represent any position of the SBGf, its officers or members. Electronic reproduction or represent any position of the SBG, its officers or members. El the Brazilian Geophysical Society is prohibited.

\section{Abstract}

Recent giant pre-salt discoveries offshore Brazil have made the Santos basin one of the most active areas for oil and gas exploration. Until recently, most of the basin has been covered only with narrow azimuth towed streamer (NATS) seismic data. The limited illumination provided by NATS data is not sufficient to image the pre-salt reservoirs through the geological complexities abundant in the area, such as variable thickness of stratified salt layer, complex salt overhangs and igneous intrusions.

Considering the huge hydrocarbon volumes of the reservoirs and the great cost associated with well placement, time-lapse (4D) seismic monitoring could be a viable solution to optimize production. However, the complexity of the overburden and the great depths of presalt carbonate reservoirs render time-lapse seismic imaging challenging. The low repeatability inherent in NATS data is likely to fail in capturing the subtle 4D response expected from this kind of carbonate reservoir.

Ocean bottom node (OBN) technology naturally addresses the illumination and repeatability issues. The lowfrequency-rich data with long offset and full azimuth coverage is ideal for velocity model building using full waveform inversion (FWI) as well as imaging. The high repeatability from OBN acquisition, together with the full azimuth illumination and the high fold, provide much reduced background 4D noise and increase the chance of retrieving subtle $4 \mathrm{D}$ signal.

Using a dataset from the central part of the Santos basin, we demonstrate the potential of OBN data for velocity model building, imaging, and time-lapse monitoring of presalt reservoirs. We further demonstrate the benefits of applying technologies such as Interbed Multiple Attenuation (IMA) and Least-Squares Migration (LSM) to maximize the value of OBN data.

\section{Introduction}

The Brazilian hydrocarbon production has been increasing rapidly since recent pre-salt discoveries in the Santos basin. In December 2018, Brazil's national oil and gas production reached 3.4 million barrels of oil equivalent per

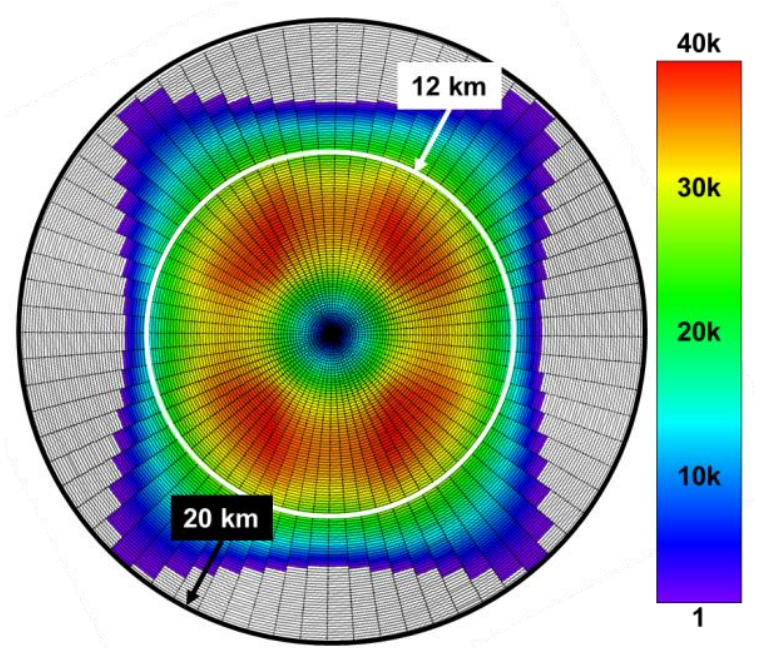

Figure 1 - Rose diagram of the acquired OBN survey. The outer black circle indicates the maximum offset ( 20 $\mathrm{km})$; the inner white circle indicates the full azimuth coverage $(12 \mathrm{~km})$.

day (MMboepd). $55 \%$ of this production is contributed by pre-salt reservoirs. It is forecasted to increase to 5 MMboepd over the next twenty years, mostly driven by the pre-salt exploration and optimization of current production.

These giant discoveries come with multiple challenges (Johann and Monteiro, 2016). The reservoirs are typically buried at depths beyond $5000 \mathrm{~m}$, under complex overburdens including salt bodies and overhangs. Salt stratification and volcanics are also common. Seismic imaging under this complex geological context is difficult. Narrow azimuth towed streamer (NATS) data often fails to deliver adequate results for imaging and velocity model building due its limited illumination. In contrast, ocean bottom nodes (OBN) data offers long offset full azimuth coverage as well as low frequencies with improved signalto-noise ratio $(\mathrm{S} / \mathrm{N})$. These allow full waveform inversion (FWI) algorithms to operate optimally to update the velocity model. Imaging is also improved thanks to the full azimuth illumination, increased fold and overall improved $\mathrm{S} / \mathrm{N}$ as nodes are placed on the deep seafloor where the ambient noise level is low.

Time lapse (4D) monitoring of these deep pre-salt reservoirs can offer great economic returns but it is not a trivial task given the expected weak 4D signals from these compact carbonate reservoirs. 4D differences between seismic surveys can be linked with changes in pressure and saturation within the reservoir and the injection regions. This can provide key information on how to improve reservoir productivity and helps in reducing risks and uncertainties in infill drilling. The impact is great for deep reservoirs where drilling costs are considerably high. 
Acquisition repeatability is the key driver for the success of 4D seismic imaging (Calvert, 2005). Thanks to the inherent flexibility of receiver positioning of OBN acquisition, repeatability between base and monitor surveys is greatly improved compared to NATS data. This considerably increases the chances of retrieving the subtle 4D differences expected from pre-salt reservoirs.

Using a dataset from the Santos basin we demonstrate the potential of OBN data to deliver an accurate and high resolution velocity model and its impact on imaging. We also present initial results of 4D seismic imaging in the presalt. To maximize the benefits of OBN data we apply technologies such as Least-Squares Migration (LSM) and Interbed Multiple Attenuation (IMA).

The OBN acquisition is comprised of 954 nodes over 36 receiver lines covering an area of $111.4 \mathrm{~km}^{2}$. The shot grid formed a dense carpet of $50 \mathrm{~m} \times 50 \mathrm{~m}$, covering a total area of about $344 \mathrm{~km}^{2}$. All nodes were deployed before shooting, meaning the nodes were "all live" during

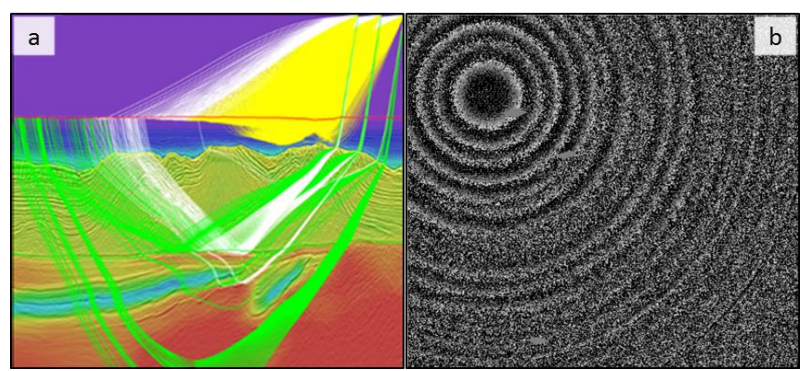

Figure 2 - a) Diving rays analysis for the OBN geometry. Shots are located at surface on the top-right. The receivers are positioned at the water Bottom (in red) Yellow rays (offsets $4 \mathrm{~km}$ to $8 \mathrm{~km}$ ) cannot penetrate deeper than the top of salt. White rays (offsets 8 to $12 \mathrm{~km}$ ) can reach the base of salt and some pre-salt layers. Green rays (offsets 12 to $18 \mathrm{~km}$ ) show penetration in all pre-salt formations. b) phase-ring $Q C$ at $2 \mathrm{~Hz}$.

recording. The azimuthal and offset coverage for all nodes deployed is depicted in the rose diagram of Figure 1, with offsets up to $20 \mathrm{~km}$. The data has full-azimuth coverage for offsets up to $12 \mathrm{~km}$.

\section{Updating pre-salt velocities using FWI}

$\mathrm{FWI}$ is able to derive high-resolution velocity models of the subsurface. Diving waves are typically the main driver for inversion. Figure 2 shows diving-wave analysis for the OBN acquisition and a phase-ring $\mathrm{QC}$ at $2 \mathrm{~Hz}$. The penetration reaches deep into the pre-salt regime. The phase-ring QC shows reasonable $\mathrm{S} / \mathrm{N}$ at $2 \mathrm{~Hz}$.

Even with the abundance of diving waves and low frequencies available in this dataset, the multitude of geological complexities can hinder the application of classical FWI formulations which are sensitive to amplitude differences between synthetic and real data. Time-lag FWI (TL-FWI) (Zhang et al., 2018) relies on minimizing the travel-time differences instead. This mitigates the issue of amplitude mismatch between modelled and real data manifesting in areas with strong velocity contrasts such as the one at hand.

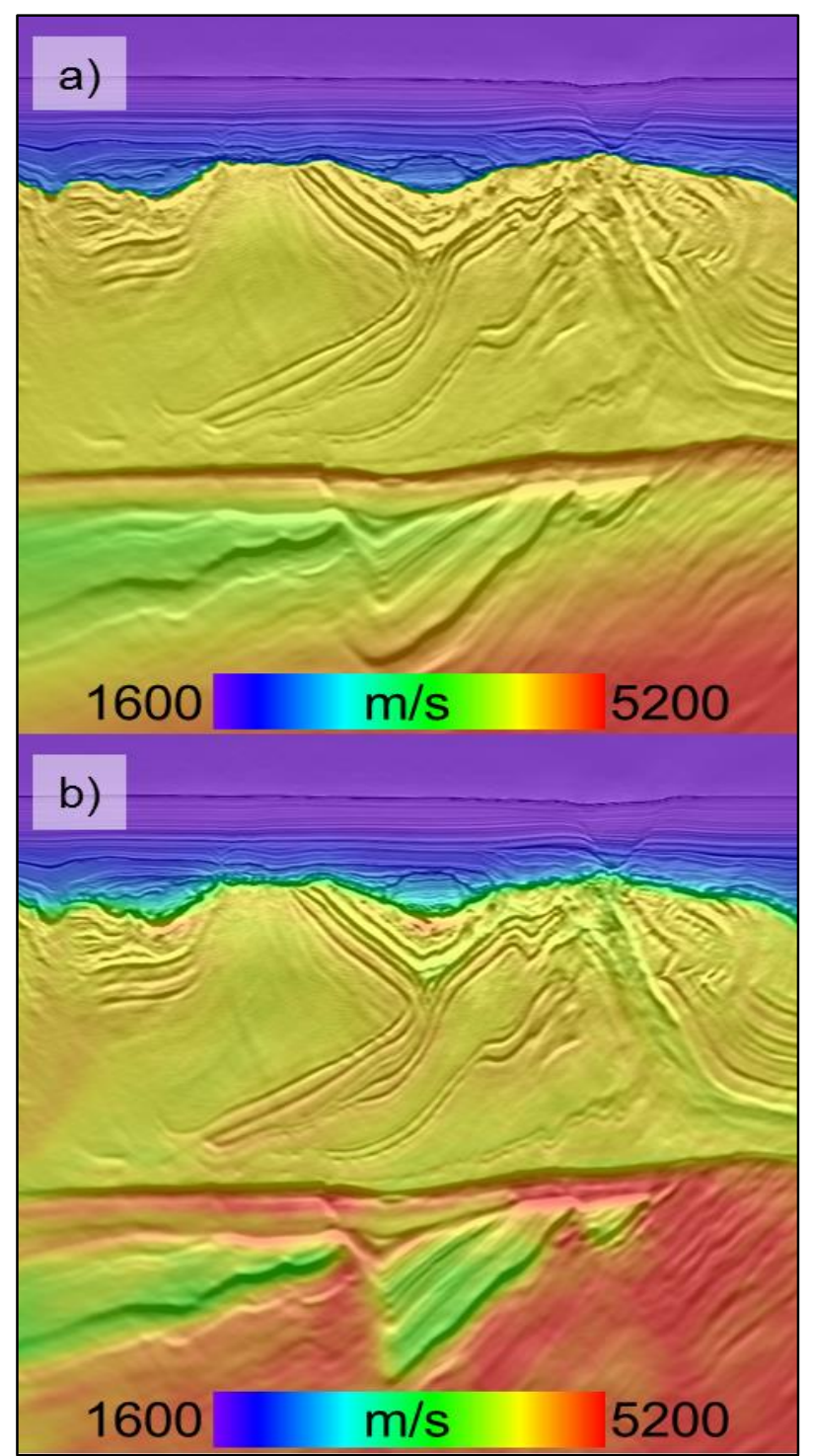

Figure 3 - Velocity overlaid on seismic image. In both cases OBN data is used for imaging; a) Legacy velocity derived using NATS data b) $15 \mathrm{~Hz} \mathrm{FWI} \mathrm{velocity} \mathrm{model}$ derived using OBN data.

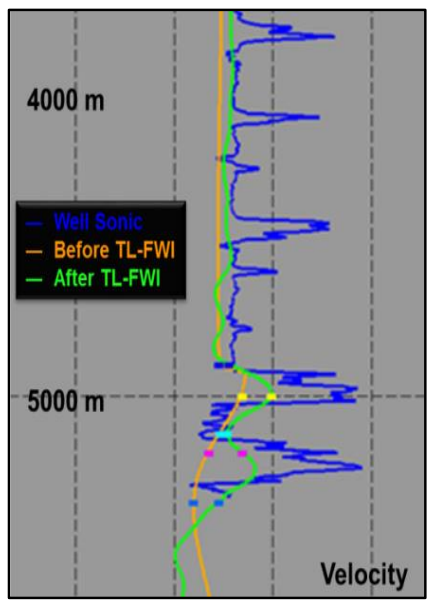

Figure 4 - Velocity profile at well location. The blue profile corresponds to the sonic log, the orange to the legacy velocity, and the green to the FWI model. The FWI velocity follows the sonic profile in the salt and pre-salt more accurately. The base of salt is around $5 \mathrm{~km}$ highlighted by the dashed line. 

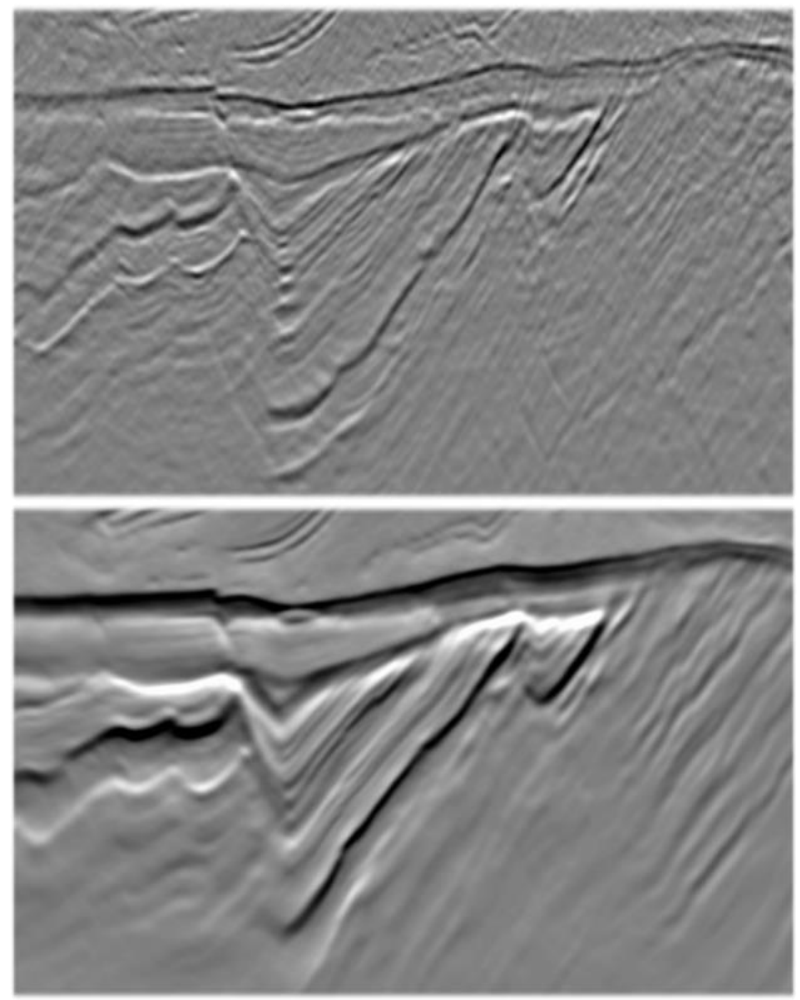

Figure 5 - Top: NATS image using the velocity model derived from NATS data. Bottom: OBN image using $15 \mathrm{~Hz}$ FWI model derived from OBN data.

Figure 3 shows the legacy velocity (derived through raybased tomography using NATS data) and the $15 \mathrm{~Hz}$ Timelag FWI velocity model overlaid on their respective images. Both are migrated using the OBN data. We observe that the salt velocity is structurally consistent with intra-salt reflectors. The pre-salt velocity has more details. The accuracy of these details is confirmed by comparing the legacy and FWI velocities against the well sonic profile in Figure 4. To further demonstrate the benefits of OBN data, Figure 5 compares legacy NATS image migrated with the model derived from NATS data to the OBN image migrated with the OBN derived FWI model. The richer low frequency content present in the OBN image is noticeable. In addition, the higher fold coverage of OBN data increases the stacking power, resulting in an image of higher $\mathrm{S} / \mathrm{N}$.

\section{D reservoir monitoring for pre-salt}

OBN data provides great repeatability for seismic reservoir monitoring. This is largely because the receivers are deployed individually to the desired locations by a remotely operated vehicle (ROV) instead of being towed by cables of multi-kilometers in length. Furthermore, nodes are placed at the deep seafloor which enjoys a considerably quieter recording environment. These factors are very important for reservoir monitoring of pre-salt targets, where the $4 \mathrm{D}$ response is subtle. Figure 6 shows the distance between sources (dS) and receivers $(\mathrm{dR})$ for the base and monitor surveys. The median for dS is around $2.2 \mathrm{~m}$ while for $\mathrm{dR}$, the median is around $2.8 \mathrm{~m}$.
Non-repeatable environmental conditions, such as tides and water velocity variations, have significant impact on 4D imaging and must be duly considered,particularly in deep-

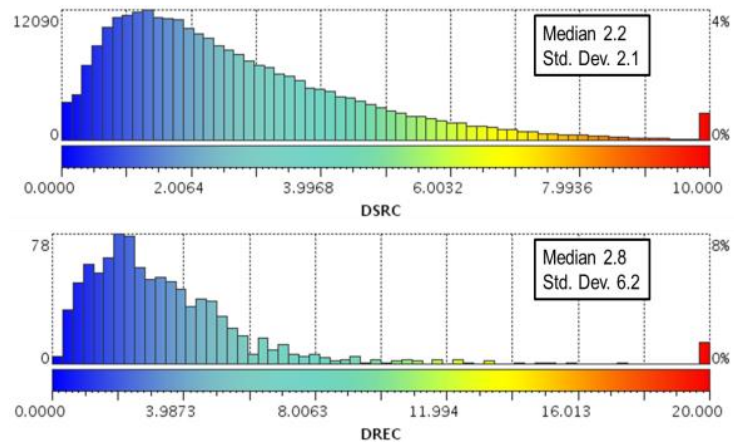

Figure 6 - Node and shot positioning repeatability. Top histogram is the difference between base and monitor shot locations (dS). Bottom histogram is the difference between base and monitor node locations $(d R)$.

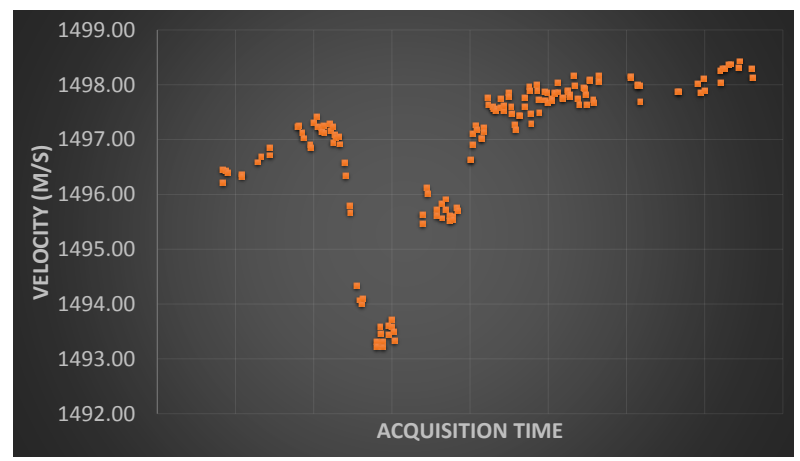

Figure 7 - The variation of measured water velocity over acquisition time.

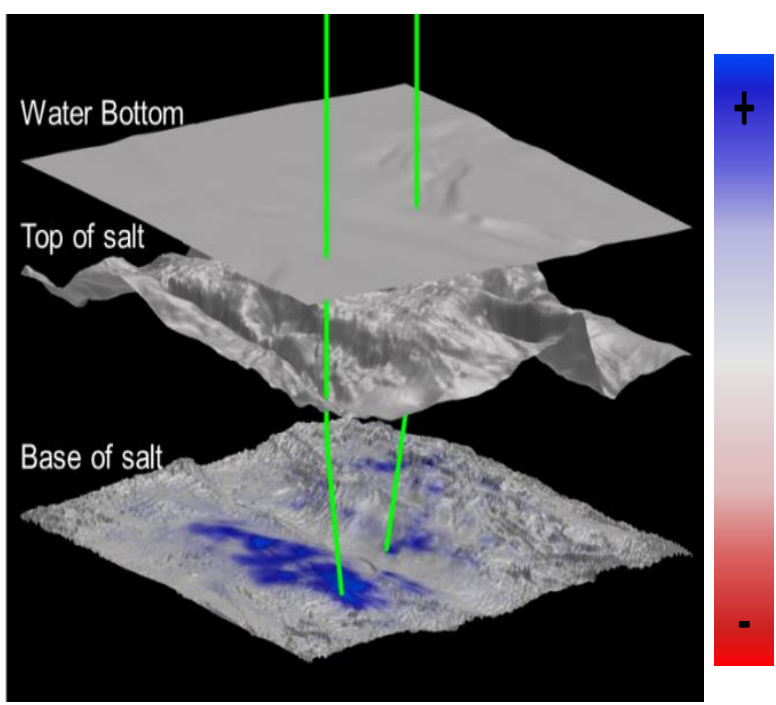

Figure 8 - SPA signal extracted at the base of salt indicating possible fluid replacement 

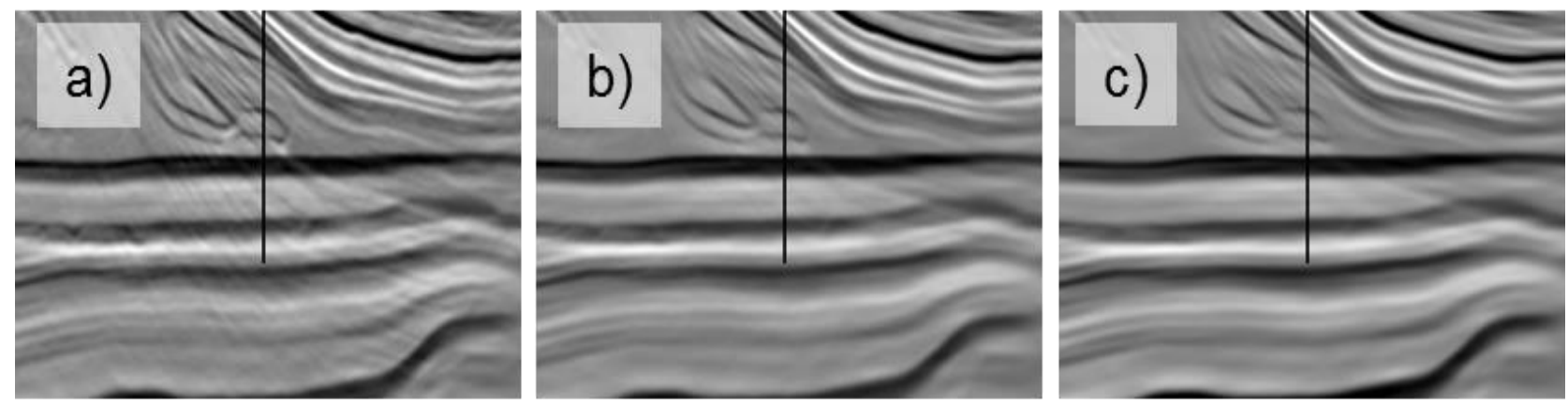

\section{baseline}
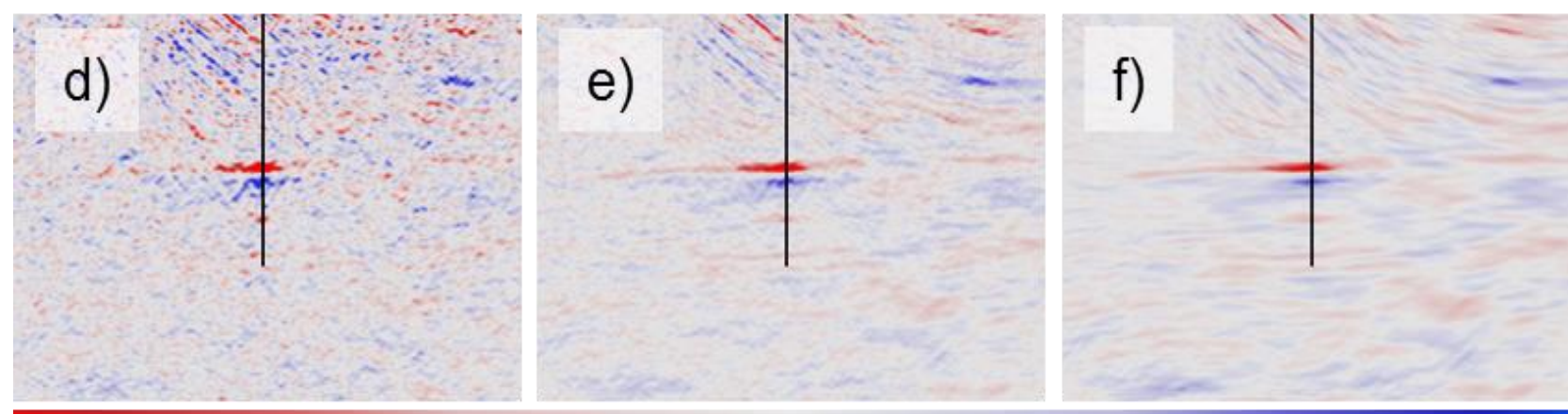

4D

Figure 9 - On top: 3D Seismic sections for a) raw migration; b) IMA applied and c) LSM on top of IMA. Bottom images: d), e) and f) are respective $4 D$ differences for raw, IMA and LSM.

water regions. Figure 7 shows the water velocity variation registered during the monitor acquisition, which reached up to $6 \mathrm{~m} / \mathrm{s}$. This change of velocity can lead to time-shifts of $5.4 \mathrm{~ms}$ in the upgoing wavefield and $16 \mathrm{~ms}$ in the downgoing wavefield measured at the water bottom for zero-offset recording. Water velocity and tidal variations can be jointly inverted with node/shot positions and node clock drift (Amini et al, 2016) and corrected for base and monitor surveys respectively (Huang et al, 2016).

Throughout the processing sequence NRMS has been significantly reduced. Before water column correction, the NRMS was around $38 \%$. After final migration, this value dropped to $2.5 \%$ at the pre-salt level.

A map showing "Sum-of-Positive Amplitude" (SPA) from the 4D difference is shown in Figure 8. The SPA signal indicates regions where possible fluid has been replaced, which seems to be consistent with the wells highlighted in green. The validity and extent of the observed time-lapse features are still under investigation.

\section{Maximizing the value of OBN data}

The Santos basin is known for its internal multiple contamination (Cypriano at al. 2015). The internal multiples are commonly interfering with the primary reflection image at the target level. Usually these are generated by the top of salt and intra-salt reflectors.

Pereira et al. (2018) proposed a method for IMA that is naturally applicable to the Santos basin geology. The method relies on separating an "overburden" region, defined here by the post-salt and salt regimes, and a "target" region, defined here by the pre-salt regime. An OBN version of this technology is applied. The $3 \mathrm{D}$ and $4 \mathrm{D}$ impact from IMA is demonstrated in Figures $9 b$ \& $9 e$. The 3D image shows less multiple contamination which can facilitate interpretation. The 4D signal is consistent with the well operations and it stands out further compared to the raw image.

OBN data generally offers a more complete data coverage compared to NAZ data. However, salt geometry and overburden complexities such as volcanic intrusions may distort the wavefields and result in non-homogeneous illumination. LSM can help in normalizing the illumination and overall improves the imaging quality.

Furthermore, LSM can improve the 4D imaging quality. The inverse Hessian carries information about source and receiver positions and normalizes their impact on the seismic image. In turn, this could correct for some of the unrepeatability between base and monitor surveys which leads to the improvement of the 4D response. Here we 
apply single-iteration LSM using Curvelet-domain matching filters as described by Wang et al. (2016). Figures $9 \mathrm{c}$ and 9 show the impact on the 3D and 4D results. The 4D signal is further improved and the overall noise level is reduced bringing more confidence to the interpretation.

Application of both IMA and LSM proved beneficial in our case, both for the 3D and 4D images. The application of IMA helped reduce the NRMS to $2.2 \%$, and when applied together with LSM, NRMS further dropped to $1.9 \%$.

\section{The road ahead}

OBN data demonstrates great potential for exploration and reservoir monitoring in the Santos basin. Seismic imaging and velocity model building greatly benefits from the full azimuth, long offset and broad bandwidth information delivered by this acquisition. It is still early to judge the full implications and impact of the observed 4D response but the results are encouraging and correlate with injection and production in a few wells.

While the test area shows a typical section from the Santos basin with considerable geological complexity, other fields in the region provide even greater challenges. For instance, Figure 10 illustrates another section from the Santos basin, showing complex salt structures and volcanic intrusions, both of which can potentially distort illumination in the pre-salt and represent a challenge for velocity model building and imaging with Kirchhoff migrations. OBN data in areas with such geological features may really provide a step-change in seismic imaging. Technologies such RTM LSM can further improve the image in such complex areas.

For the time being the main hurdles for acquiring more OBN data are turnaround and cost. The seismic industry has made strides to reduce these. An overview of possible low-cost seismic technologies for pre-salt monitoring are discussed in Lopez et al, 2017. Simultaneous source (blended) acquisition for OBN is becoming more popular with relatively broad acceptance for 3D imaging, for example see Zhuang et al. (2017). Some promising synthetic tests for blended 4D seismic monitoring have also been made (Davies and lbram, 2015). Looking further ahead into the future, autonomous systems with semipermanent nodes could be feasible (Lopez et al. 2018).

\section{Conclusions}

We have shown that OBN data is capable of providing substantial uplifts for velocity model building and imaging compared to NATS data. The OBN data also provide good repeatability for pre-salt reservoir monitoring. Conventional 4D processing achieved a final NRMS of $2.5 \%$. With the application of IMA and LSM techniques, we were able to enhance the 3D image and further reduce the 4D NRMS to a value of $1.9 \%$. The resulting $4 \mathrm{D}$ section has visible benefits in terms of reduction of noise and signal continuity.

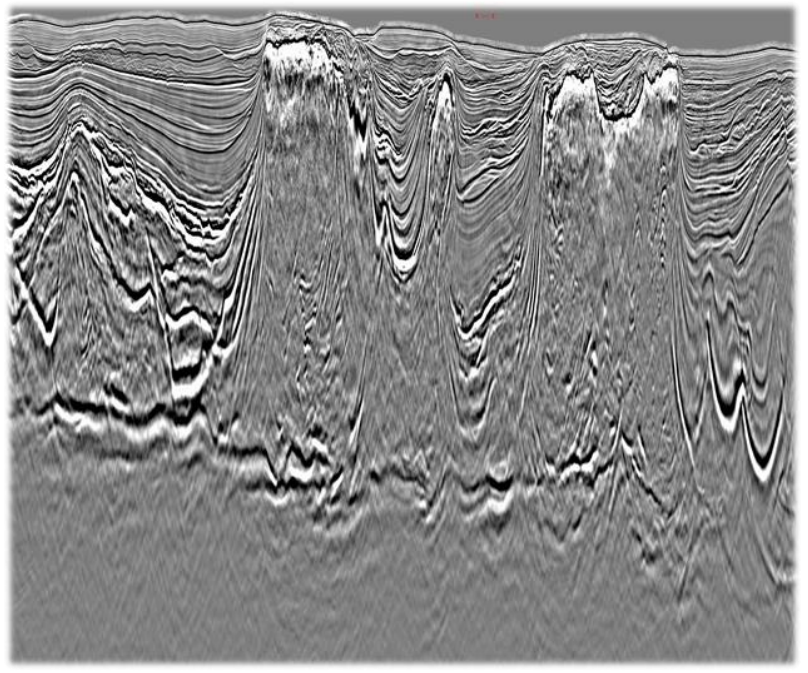

Figure 10 - Other example in the Santos basin. NATS image shows complex overhangs in the east side of the section and presence of igneous intrusions at west. They cause challenges for illumination and velocity estimation, which are possible to benefit from OBN acquisition.

\section{Acknowledgments}

We would like to thank Petrobras and CGG for their permission to publish this work. Also, we thank Petrobras Exploration, Reservoir and Production Asset teams, together with Shell and Petrogal staff for their contributions and discussions during the technical meetings.

\section{References}

AMINI, A., PENG, H., ZHANG, Z., HUANG, R., YANG, J., 2016, Joint inversion of water velocity and node position for ocean bottom node data: $86^{\text {th }}$ Annual Meeting, SEG, Expanded Abstract, 5490-5494.

CYPRIANO, L., F. MARPEAU, R. BRASIL, G. WELTER, H. PRIGENT, H. DOUMA, M. VELASQUES, J. BOECHAT, P. DE CARVALHO, C. GUERRA, AND C. THEODORO, 2015, The impact of inter-bed multiple attenuation on the imaging of pre-salt targets in the Santos basin offshore Brazil: 77th EAGE Conference \& Exhibition, Extended Abstracts, N114-06.

DAVIES, D. M. AND IBRAM, M., 2015, Evaluating the Impact of ISS HD-OBC Acquisition on 4D Data: 77th EAGE Conference \& Exhibition, Extended Abstracts, N101 05.

HUANG, R., WANG, P., NIMSAILA, K., VU, M., 2016, Angle-dependent Water Column Statics Correction through Sparse TauP Inversion. 78th EAGE Conference \& Exhibition.

JOHANN, P. AND MONTEIRO, R., 2016, Geophysical Reservoir Characterization and Monitoring at Brazilian Pre-Salt Oil Fields, Offshore Technology Conference, OTC-27246.

LOPEZ, J. L, CHALENSKI, D. A., AND GRANDI, S., 2018, Developing A Fully Autonomous Marine Seismic Acquisition System For Low-Cost On-Demand Reservoir 
Monitoring: EAGE Marine Acquisition Workshop, Extended Abstracts.

LOPEZ, J. L., COX, B., HATCHELL, P., \& WANG, K., 2017. Technology Options for Low-Cost On-Demand Seismic Monitoring in Deepwater Brazil. 15th International Congress of the Brazilian Geophysical Society. Rio de Janeiro.

PEREIRA, R., MONDINI, D., AND DONNO, D., 2018, Efficient 3D internal multiple attenuation in the Santos basin: 80th EAGE Conference and Exhibition, Extended Abstracts.

WANG, P., A., GOMES, Z., ZHANG, AND M., WANG, 2016, Least-squares RTM: Reality and possibilities for subsalt imaging: 86th Annual international Meeting, SEG, Expanded Abstracts, 4204-4209.

ZHANG, Z., MEI, J., LIN, F., HUANG, R., AND WANG, P., 2018, Correcting for salt misinterpretation with fullwaveform inversion: 88th Annual International Meeting, SEG, Expanded Abstracts, 1143-1147.

ZHUANG, D., SHAO, G., KHALIL, A., NOLTE, B., PARAMO, P., VINCENT, K., 2017, Deblending OBC data with dual and triple simultaneous sources offshore Trinidad: 87th Annual International Meeting, SEG, Expanded Abstracts, 1143-1147. 